\title{
Protecting care home residents from mistreatment and abuse: on the need for policy
}

This article was published in the following Dove Press journal:

Risk Management and Healthcare Policy

19 November 2015

Number of times this article has been viewed

\section{Amanda Phelan}

School of Nursing, Midwifery and Health Systems, University College Dublin, Ireland
Correspondence: Amanda Phelan School of Nursing, Midwifery and Health Systems, University College Dublin, Belfield, Dublin 4

Tel +353 | 7166482

Fax +353 | 7166450

Email amanda.phelan@ucd.ie

\begin{abstract}
With a rising older person population with increasing life expectancies, the demand for care homes will increase in the future. Older people in care homes are particularly vulnerable due to their dependencies related to cognitive and/or functional self-care challenges. Although many care homes provide good care, maltreatment and abuse of older people can and does occur. One major step in preventing and addressing maltreatment in care homes is having comprehensive and responsive policy, which delineates national expectations that are locally implemented. This paper examines the literature related to maltreatment in care homes and argues for policy based on a multisystems approach. Policy needs to firstly acknowledge and address general societal issues which tacitly impact on older person care delivery, underpin how care homes and related systems should be operationalized, and finally delineate expected standards and outcomes for individual experience of care. Such a policy demands attention at every level of the health care and societal system. Furthermore, contemporary issues central to policy evolution in care homes are discussed, such as safeguarding education and training and fostering organization whistle-blowing protection.
\end{abstract}

Keywords: care homes, maltreatment, policy, older people

\section{Introduction}

The development of care homes resulted from a societal need to look after vulnerable people with complex needs of care. Care homes represent a communal environment where health and social care staff meet the cognitive and physical needs of residents on a 24-hour basis. The terminology to describe care homes is diverse, such as group homes, nursing homes, residential care facilities, and long-term care for older people. ${ }^{1}$ In addition, Daly and Szebehely ${ }^{2}$ observe that care delivery within such facilities can vary and is dependent on issues such as historical and cultural influences, government funding, and intergenerational solidarity. One of the most fundamental issues for these care facilities is to ensure that residents are free from maltreatment, and having appropriate, multilevel systems and policies in place to prevent the abuse of older people is, consequently, essential. This is particularly important in the context of the diverse and complex vulnerabilities that the residents have. Yet, maltreatment in formal care tends to be taboo and can be undisclosed publicly, due to factors such as being unrecognized, trying to avoid negative publicity, workplace conditioning and culture, personal fear of repercussions following disclosure of care delivery concerns and staff confusion regarding confidentiality. ${ }^{3-5}$ Furthermore, the experience of maltreatment in care homes cannot be separated from broader institutional-level and, indeed, societal-level issues. 
Consequently, in this paper, I argue for a comprehensive multisystem approach to address such maltreatment in policy and practice.

\section{Older people}

Defining "old age" can be challenging. Some commentators ${ }^{6}$ consider the precise distinction of old age to be formally evidenced in Bismarck's creation of rudimentary welfare pensions in the 1880 s for people older than 65 years. Consequently, many countries, such as Ireland and the UK, recognize 65 years of age as the gateway to old age. However, other entities, such as the United Nations ${ }^{7}$ and the World Health Organization (WHO) ${ }^{8}$ take the lower threshold of 60 years of age, observing that chronological aging is an insufficient measure for the aging process. The redefining of older people is also influenced by the increasing complexity of old age. As the life expectancies of the population grow, the subdivision of old age has emerged as the "young old" and "old old". 9

The number of older people is increasing in all countries as well as the relative percentage of older people within national populations. ${ }^{10}$ The greatest proportionate increase is in the older old age group. ${ }^{11}$ Consequently, concurrent with this demographic change is an increased demand for care home places as age is a prominent risk factor for health decline in the context of both physical and cognitive well-being. ${ }^{12}$ An older person may need to be admitted to a care home due to the following three main reasons: 1) when his/her ability to function independently has become challenged; 2) when available supports have become challenged, and therefore, living at home is considered risky or too difficult; and 3) when he/she requires recuperation following an acute illness or surgery or requires end-of-life care.,13 Certainly, admission is associated with an increasing vulnerability in the older person's personal circumstances wherein living independently or with available supports becomes too challenging as risk factors increase.

\section{Elder abuse}

Traditionally, maltreatment in relation to older people has been considered "elder abuse" and is closely related to interpersonal relationships. Elder abuse is a form of abuse that has only received formal attention in recent years. Baker ${ }^{14}$ published an article that identified the maltreatment of older women. Since that publication, a corpus of knowledge has emerged, which has focused on defining, identifying, and ameliorating elder abuse. Although the issue of defining elder abuse has been contentious, ${ }^{15}$ the United Nations ${ }^{16}$ and the
$\mathrm{WHO}^{17}$ drew on the definition of elder abuse by Action on Elder Abuse ${ }^{18}$, a charitable organization in the UK, that is

A single or repeated act or lack of action occurring within any relationship where there is an expectation of trust, which causes harm or distress to an older person.

This definition has limitations, as it centers around who is the perpetrator and also the subjective interpretation of the "abusive" act by the older person. Mowlam et al ${ }^{19}$ observed that there is a lack of distinction between elder abuse and other forms of interpersonal conflict and problems with classifying experiences. Elder abuse has also been divided into the following typologies: physical abuse, sexual abuse, financial/material abuse, psychological abuse, and neglect and discriminatory abuse. However, the issue of self-neglect is confusing with it being recognized as elder abuse in the policy of some jurisdictions while being specifically excluded in others. Another important issue is that formalized definitions have been generated by researchers, case management practitioners, and legal commentators. Studies that consider an older person's definition of elder abuse have drawn on expanded understandings which highlight ageism, the loss of self-determinism, the relevance of age itself, and the deficits in statutory services. ${ }^{19-23}$

\section{Prevalence of abuse in community settings}

Most prevalence studies of elder abuse have been undertaken in community settings with older people with cognitive capacity. These studies indicate that elder abuse ranges between $\sim 2 \%$ and $10 \%,{ }^{2,24-26}$ with one study highlighting that only 1:24 cases come to the attention of formal services. ${ }^{27}$ Prevalence studies of elder abuse within populations of older people with dementia are more challenging to conduct and generally focus on data collected via caregivers. However, such studies demonstrate a much higher prevalence of $27.9 \%{ }^{28}$ and $62.3 \% .^{29}$

\section{Prevalence of abuse in care homes}

Studies on the prevalence of maltreatment within care home environments are sparse and tend to focus on staff perpetration of abuse..$^{30-32}$ There are marked differences in maltreatment in the domiciliary environment and care home environment. First, although there is an expectation of trust, in care homes this is based on formal contracts of care delivery by paid staff. Second, living in a care home may mean sharing room space with another unfamiliar resident and certainly mean the negotiation of communal spaces, such as 
recreation or dining areas. In being admitted to a care home, the individual becomes part of a community wherein it is impossible to avoid contact with other community members (staff and/or other residents). In addition, even in the most open care homes, there is generally some submission to organizational routines, with regard to visiting times, sleeping times, meal times, recreation times, or medication times. Compounding these characteristics of care homes is the fact that many older people experience reduced social networks as they age and care homes tend to have inward communication (ie, visitors) with the external world rather than multiple external communication patterns (older residents going out to the community).

Commentaries on abuse in care homes can be traced back to the 1960 s and 1970 s. ${ }^{33,34}$ Similar to the community setting, resident risk factors, such as having a negative functional and cognitive status, have been shown to be related to maltreatment. ${ }^{32,35}$ However, an additional risk factor is that care home populations tend to be in the older old age group, thus increasing potential vulnerability. ${ }^{36}$

Situational risk factors consider the specific context that leads to abuse, for example, poor supervision or a closed culture of care. ${ }^{36}$ In the study by Drennan et al, ${ }^{32}$ high levels of staff burnout, ageist attitudes, and the experience of residentrelated and facility-related issues were associated with neglect of residents, while, similar to the findings of Phillips and Guo, ${ }^{31}$ care facility size, staff nationality, burnout, and low job satisfaction were associated with physical abuse.

Prevalence figures of abuse in care homes vary according to data collection sources (eg, observing the abuse by a colleague and self-reports of abuse), methodological approaches, and timescales used, ${ }^{32}$ with neglect and psychological abuse perpetrated by staff members being the most common form of abuse..$^{33,37,38}$ An early prevalence study in the US indicated that $36 \%$ of staff witnessed abuse in the previous year. ${ }^{30}$ In the German study by Goergen, ${ }^{39}$ it was found that $70 \%$ of staff had perpetrated abuse in their interactions with older people, while in Israel, this figure was identified as $54 \% .^{40}$ In Ireland, Drennan et $\mathrm{al}^{32}$ identified that $57.6 \%$ of staff had observed another staff member perpetrating abuse in the previous 12 months. However, it is likely that such figures are underestimations. ${ }^{41}$

In addition to the dyadic forms of abuse identified earlier in this paper, systemic institutional abuse and abuse related to physical and chemical restraints as well as inappropriate environmental conditions and impoverished staffing levels, high staff turnover, and an inappropriate skill mix have been highlighted in the literature. ${ }^{30,32,39,40,42-44}$ A notable observation by Hyde et $\mathrm{al}^{45}$ is that the convergence of multiple minor changes or deficits could predispose to the "perfect storm," wherein individually such issues are manageable, but when occurring together or allowed to deteriorate, the quality of care could be significantly affected.

In relation to skill mix and staff ratio, the level of dependency of the older person (cognitive or physical) should have an impact on the level of required staff competencies to avoid inappropriate responses to the needs of care of the residents. ${ }^{31,45}$ Harrow Council ${ }^{46}$ defines institutional abuse as:

[...] the mistreatment of people brought about by poor or inadequate care or support, or systematic poor practice that affects the whole care setting. It occurs when the individual's wishes and needs are sacrificed for the smooth running of a group, service or organization.

In particular, neglect of residents can be associated with institutional-level abuse. ${ }^{40}$ Furthermore, issues such as small isolated facilities, ${ }^{31}$ institutional size,${ }^{31}$ and for-profit status have been linked to higher rates of mistreatment, ${ }^{47-49}$ which may be influenced by a desire to maximize profit margins. Another study has also observed that the general business environment affects ethical conduct of management and recommended that such issues are important policy considerations for positive service delivery outcomes. ${ }^{50}$

\section{Using a human rights lens}

Within the domain of elder abuse, using a human rights approach has been integrated into both viewing abusive activities and a benchmark to respond to rights violations $s^{51-54}$ and is closely aligned to the concept of personhood and personcentered care. Upholding human rights is considered a "first responsibility" of all governments ${ }^{53}$ and provides protection for vulnerable groups. ${ }^{55} \mathrm{~A}$ human rights lens has engendered recent debates regarding the potential of a specific human rights convention for older people ${ }^{56}$ with a specific openended working group being established in 2010 within the United Nations. The advantages of such a convention are seen to counteract tacit obstacles to the enjoyment of human rights by older people such as age discrimination and ageism. ${ }^{57}$ Within an application of human rights to older people in nursing homes, Quinn ${ }^{58}$ argues that policy priorities have favored an anti-human rights approach in the expansion of care homes without a consideration of other novel options to allow older people to remain in their communities. A rights-based approach can illuminate inconsistencies in relation to care homes such as the right to liberty. For example, often, leaving the care home is not permitted without an accompanying 
person, even in the event of having full capacity to do so. Moreover, the potential to return to community living is not promoted as a viable option in care for many residents. Issues related to other rights pertain to the right to privacy, the right to a family life, the right to be free from torture, and inhuman or degrading treatment or punishment. In addition, the right to an effective remedy can also be challenged when the issue of ageism in health care is considered.$^{57}$ Furthermore, the $\mathrm{WHO}^{59}$ has highlighted the close relationship of sexual rights and human rights; yet, Benbow and Beeston ${ }^{60}$ argue that issues such as a lack of accommodation (information and pragmatic) to physical and cognitive health challenges, a lack of privacy, environmental limitations, and ageist attitudes can prevent an older resident's fulfillment of sexuality needs, despite this being an essential part of an individual's life. ${ }^{59,61}$ Although many of these issues are underresearched in the context of care homes, a rights-based approach has very fundamental advantages in terms of policy articulation in care homes.

\section{Aggression by residents}

A focus of recent care home research is the area of resident to resident aggression (RTRA). As with any human interaction, there is a potential for conflict. Although conflict may occur between residents with and without cognitive challenges, there is a high prevalence of older people in care homes who have dementia with many presenting with behavioral and psychological symptoms of dementia. These symptoms include aggression, agitation, and psychosis ${ }^{62}$ all of which may have an impact on the safety of coresidents. While the maltreatment of residents in care homes has generally focused on staff-resident maltreatment, RTRA is the most common form of abuse. ${ }^{63}$ RTRA may be defined as

$[\ldots]$ negative and aggressive physical, sexual or verbal interactions between long term residents that in a community setting would likely be construed as unwelcome and have a high potential to cause physical or psychological distress in the recipient. ${ }^{64}$

Despite its significance in quality of life for older people in nursing homes, RTRA victims can be more neglected by staff and RTRA has both physical and psychological consequences for victims. ${ }^{65,66}$ In addition, response systems can lack clarity with Lapuk ${ }^{67}$ commenting that it is considered a normalized part of living in a nursing home. Yet, one study in the United States ${ }^{68}$ identified that $6 \%$ of older people had police contact after placement in care homes, with the major referral issue being RTRA. In a qualitative study using staff members in care facilities, Rosen et al ${ }^{69}$ identified 35 types of RTRA within the domains of physical abuse, verbal abuse, and sexual abuse, with verbal aggression being the most prevalent. These types were further reduced by a subsequent work by Pillemer et al, ${ }^{64}$ and the following five categories resulted: invasion of privacy, room-mate altercations, hostile interpersonal interactions, unprovoked actions, and inappropriate sexual behaviors. An important finding in the study by Rosen et $\mathrm{al}^{69}$ related to policy is that many of the identified incidences were considered to have triggers, particularly related to communal living experiences and adjusting to a multiethnic and multicultural environment. Moreover, the study suggests that comingling of residents with and without dementia is a significant factor in RTRA. Acknowledging the prevalence and impact of RTRA within emerging research, it is essential that appropriate responses are engendered in policy, taking into account the orientation to communal living, to ensure the safety of residents.

Closely connected to RTRA is the prevalence of resident to staff conflict, which has been identified as a common staff experience. Drennan et $\mathrm{al}^{32}$ reported a prevalence of $91.8 \%$ in a $12-$ month period, and Morgan et $\mathrm{al}^{70}$ reported a prevalence of $88.9 \%$ in the previous month. These conflict situations were closely connected to dementia behaviors. Thus, in relation to both RTRA and resident to staff conflict, a fundamental issue for policy in care homes is that staff are equipped with appropriate skills and competencies to manage challenging behaviors in a contemporaneously, sensitive and competent way to prevent occurrences and prevent escalation of such situations. The imperative of having appropriately trained and, indeed, specialist staff to meet the acuity needs of residents is an issue policy has to acknowledge as populations in care homes require specific and specialist person-centered care, which enables outcomes focused on the quality of care.

\section{The focus of policy}

Vulnerable older people are high consumers of care home services, yet issues of mistreatment in such facilities represent a serious societal issue..$^{51,71}$ There have been concerns globally regarding care homes where negligent practices, poor service delivery, and maltreatment have been illuminated in scandals, via means such as undercover documentary evidence, inspection reports, public inquiries, or serious case reviews. ${ }^{72-76}$ The objective of such a public scrutiny is to highlight poor care, learn lessons, improve service delivery, and make relevant policy recommendations. With regard to the overall function of policy, it provides a set of 
guiding principles and a statement of intent with the purpose of achieving defined outcomes. However, in the history of care homes, the tendency is that policy is reactive to such scandals rather than being proactive to prevent them. ${ }^{15}$ Thus, the need for comprehensive and dynamic policy to prevent abuse and protect residents is fundamental to care delivery. Moreover, as more research is undertaken into the context and experience of living in a care home, the imperative nature of responsive policy is apparent in order to meet the needs of the emerging care home population.

Protecting residents from harm requires a multifocused, multisystem comprehensive policy that is underpinned by principles of resident autonomy and excellence in quality care. Fundamentally, a person-centered approach is central to care delivery, where staff engage in therapeutic relationships that prioritize personhood, self-determination, respect, and dignity. ${ }^{71,77,78}$ Policy aims to potentiate positive aging, ${ }^{79}$ promote social integration, and assimilate lessons learned within inquiries. ${ }^{45}$ However, the individual experience of care excellence does not always occur in a cohesive way. The national policy needs to identify expected standards grounded in evidence-based practice to facilitate responsive services that are consistent in delivery. ${ }^{80}$ Understanding the alignment of the national policy to resident experience is potentiated using an ecological, systems-based approach. ${ }^{81}$ Aligning positive practices within the macro-, meso-, exo-, and microsystems underpins safe care, and each level is implicitly interconnected. In the context of care deficiencies, it is imperative that a multisystems approach requires attention not only to emergent issues but also on how such issues are interrelated to produce maltreatment, missed care, ${ }^{82}$ failure to rescue,${ }^{83}$ or never events. ${ }^{84}$ Consequently, it is the organizational conditions within which care deficits occurred that are examined as well as the particular negative outcome(s) itself.

Policy needs to acknowledge the macrosystem within which beliefs and values of societies in relation to older people emerge and acknowledge how such perspectives (such as ageism) can have an impact on care delivery and care experience. For instance, a global debate is necessary on the need to diversify care delivery options as care homes are the most dominant and, in many countries, unilateral way of caring for older people with heightened care needs. Funding needs to be flexible taking into account need and choice. Quinn ${ }^{58}$ observed, for example, that disparate funding for domicile living as opposed to care homes means that it could be more economical and congruent to the individual's choice to increase care in terms of services delivered to a person's home, yet, the person may have little option but to enter a care home as funding availability is separately ring-fenced for both settings. Indeed, the ethical issue of prioritizing the older person's wishes and happiness with choice can be subsumed by family demands, a dominant focus on risk or medical advice.$^{85}$ In addition, apart from planned rehabilitation or convalescent care, few care homes integrate a focus on the potential to return to the domicile. Once such perceptions are acknowledged, response systems can be orientated toward addressing deficits. As discussed earlier, benchmarking care delivery against human rights standards also provides a way of ensuring that paternalistic and ageist practices are exposed and addressed appropriately.

The presence and influence of regulatory bodies for care homes can have a significant impact on quality of care, risk management, and monitoring of such care. ${ }^{15}$ Such regulatory bodies require legislative imperatives in terms of mandated monitoring, inspection, and registration of care homes in order to promote standardized care experiences and protect each resident from harm. Another example where comprehensive legislation is essential is in relation to mental capacity. Legislation needs to promote a functional approach to capacity and prescribe care mechanisms that promote the individual's will and preference, particularly when capacity is diminished.

Within an exosystem, the culture of systems of care needs to be examined, for example, profit or not-for-profit care homes, mission statements, leadership and management, skill mix, staff retention, and other processes of localized care delivery. Thus, this considers issues such as how the organization has an impact on how staff conduct their work. ${ }^{45}$ Having robust risk management systems in place is essential to identify, respond, manage, and monitor risk ${ }^{86}$ and needs to be both proactive and reactive. Risk management occurs on multiple levels, for example, having regular risk management assessments for individual residents (based on personal characteristics) and risk management of the environment (physical setting, staff ratios, health, and safety). In particular, the management of local complaints needs to be clarified in policy where responses to any resident complaints of maltreatment are not met with threats of their having to move from the nursing home ${ }^{43}$ representing a further exacerbation of abuse.

The third level, the mesosystem, is articulated on how the residents' autonomy, rights, dignity, or social connectedness (family, community) is maintained and promoted. For example, an important mechanism to support an older person's rights is accessibility to an independent advocate, 
who can counteract powerful voices of families and professionals and can give strength to the older resident's perspective, will, and preference. It also encompasses how staff are trained and demonstrate competency in areas such as person centeredness, regular timed resident assessment, safeguarding, communications (relatives and residents), and resident need-related competencies. Again, the use of a human rights lens can stimulate staff to question poor practice and discuss how rights can be promoted. This is particularly relevant in the context of dementia-related care, where decisions may be taken on behalf of the resident in a paternalistic way. A final issue worthy of specific consideration is that of safeguarding residents from financial abuse. This form of abuse may be occurring without the older person's knowledge and is one form of abuse that may be remote to the older person. ${ }^{15}$ For example, the management of bank accounts and other assets of the older person may be allocated to a third party (eg, through power of attorney), particularly in the case of cognitive impairment, and siphoning assets or not acting in the resident's best interests would be an instance of financial abuse. Policy needs to give guidance in this area and also in relation to strict accountability and management of any funds the care home manages on behalf of the resident.

Finally, a microsystem's focus protects residents in the context of promoting the quality of care within everyday direct experience. In the context of maltreatment, this includes not only things such as interpersonal relationships but also tacit, direct experiences related to areas as diverse as environmental planning, palliative and end-of-life care, nutrition, socialization, engagement, availability of suitable and desirable activities, and appropriate, holistic, individualized care that is outcome based for positive living and dying.

Using a comprehensive multisystems approach allows the many factors that contribute to maltreatment in care homes to be addressed. Thus, abuse of older residents is not a unidimensional phenomenon, and policy needs to incorporate the diverse areas that influence the resident's experience of care delivery.

\section{Review of inspection reports on care homes}

Policy development is enhanced through the integration of findings from regulatory inspection reports. These reports identify important issues of concern and point to areas of potentiating risk management. Two recent reviews examining issues arising from official reports on elder mistreatment in care homes identify similar issues. ${ }^{45,87}$ Hyde et al ${ }^{45}$ suggest four organizational factors that affected the quality of care in an examination of nine published reports from 2000 to 2009 in the UK and Ireland. These are infrastructure, management, staffing, resident population characteristics, care home culture, and macrostructural factors such as changes in ownership, financial pressures, or ineffective external agency monitoring. In a review of eleven care homes deregistered by the Irish Health Information and Quality Authority in the period 2010-2012, Lafferty et al ${ }^{87}$ found similar organizational issues leading to failures in care, namely, environmental factors, institutional factors, practice factors, and resident-related factors. These findings also reinforce the necessity for policy to take a comprehensive multisystemsbased approach. ${ }^{81}$

\section{Education and training}

For maltreatment to be recognized, staff, residents, and the general public need to be aware of what precisely constitutes abuse. This also requires a critical approach to taken for granted ageist attitudes in society, policy, and legislation. One of the prominent ways of raising awareness is through staff education and training as well as public campaigns, which emphasize anti-ageist messages. Many studies have identified raised staff awareness of maltreatment via educational initiatives. ${ }^{88,89}$ However, these studies tend to be single-point evaluations, many undertaken at the end of the training program, where sensitivity to maltreatment is heightened. Some studies identified the limitations of current educational programs ${ }^{89}$ with Smith et $\mathrm{al}^{90}$ emphasizing that a focus on more interactive and personally relevant programs has the ability to imbue a deeper understanding of the issue. Being aware of all aspects of maltreatment is essential, but equally is the broader focus on ensuring that staff competencies and skill mix are appropriate and match the needs of the residents and that the environment is, itself, safe and conducive to enhancing the quality of life of the residents. In reality, education should be guided by a continuous practice development focus on safeguarding residents, which not only meets the criteria of any regulatory body but also responds to an objective implementation of the standards of care supported by independent assessment and which integrates a critical consideration of how local problematic issues can be addressed. The challenge for the national policy is to ensure that adequate standards are guaranteed, while ensuring that localized problems are attended to on a continuous basis, using a risk management approach.

\section{Whistle-blowing}

Whistle-blowing involves the disclosure to formal authorities of information that is abusive, illegal, or dishonest 
within an organization. Within policy for older people in care homes, the facility of whistle-blowing is important for ensuring that appropriate standards and patient's safety and disclosure of harm or potential harm are considered an absolute obligation. ${ }^{91}$ Care homes are particularly important sites for having comprehensive whistle-blowing policies as resident issues, such as cognitive impairment, unequal power relationships, dependency, fear of repercussions, and having no alternative suitable domicile, can make disclosure by residents difficult. Yet, in some circumstances, there remain negative consequences that are experienced by whistle-blowers. ${ }^{92,93}$ For example, although frontline staff are aptly placed to report concerns, ${ }^{4}$ reporting may lead to the staff member being ostracized, demoted, scapegoated, or even resigning over the negative responses. ${ }^{92}$ However, within regulated professions, sanctions may be enforced if whistle-blowing does not occur leading to a potential dilemma, namely, the fear of consequences of reporting and the fear of consequences of not reporting that may be influenced by loyalty to colleagues or a belief that their voice would not be heard or make a difference. However, some commentators' question the value of this dichotomous choice, suggesting that there should be a spectrum of responses that equate to the gravity of the infringement. ${ }^{4}$

Within the context of serious case reviews of neglect, maltreatment, or malpractice, Kelly and Jones ${ }^{3}$ note that there are two avenues of whistle-blowing: internal within the organization or external, such as to a regulatory body, the police, or media. However, a robust policy demands a concerted response in the context of the obligation to investigate in a comprehensive way and within a defined timespan. Yet, studies have demonstrated that even in the event of a whistle-blower disclosing a concern, these reports may be ignored or get only a token response. ${ }^{73,91}$ Such poor care can then become common and, consequently, assume a status of normalization. ${ }^{3}$ Thus, to avoid such challenges, policy needs to foster disclosure of poor care and ensure that this is within a culture of nonvictimization and appropriate, timely response follow-ups.

\section{Conclusion}

This paper has considered the issue of abuse in care homes for older people and specifically argues for a multisystem approach to policy. Policy that neglects the multiple layers of protection will ultimately fail and fail consistently and spectacularly. The experience of care is dependent on alignments of a multisystems approach from the national policy to local policy that dictates organizational systems and person-centered outcomes. Such organizational systems filter down to direct care provision and the experience of care. Ensuring care is delivered in a person-centered way means personhood and human rights are fully articulated and adopted as a standard in all aspects of care delivery. As care standards expressed in policy must be guaranteed, independent regulatory bodies, supported by legislation, are essential components of policy implementation. Policy must direct that staff have regular training in issues related to everyday interactions with older people and sensitive person-centered care delivery. This essentially includes a proactive and reactive risk management ethos, which must be balanced with residents' autonomy, will, and preference. The emergence of issues connected to the context of care and understanding of maltreatment in recent research also demonstrates the need for continuous policy reform. For example, issues such as RTRA must be acknowledged and appropriate care management implemented. This means having competencies to deal with the complexities of behavioral and psychological symptoms of dementia as well as acknowledging and managing issues related to normal interpersonal conflict. Policy must also ensure safe open disclosure or whistle-blowing regarding issues of concern. The imperative is to ensure residents, staff, relatives, and others are encouraged to communicate concerns that are dealt with contemporaneously and in a nonvictimized way. Finally, to use the adage "the proof is in the pudding" only then, through a cascading national policy for implementing quality of care and a quality-assured local policy of guaranteeing care, can protecting residents in care homes be a realistic and viable experience.

\section{Disclosure}

The author reports no conflicts of interest in this work.

\section{References}

1. Phelan A, McCormack B. Exploring Nursing Expertise in Residential Care for Older People in Ireland. Dublin: AIGNA and NHI; 2013.

2. Daly T, Szebehely M. Unheard voices, unmapped terrain: care work in long term residential care in Canada and Sweden. Int J Soc Welf. 2012;21: 139-148.

3. Kelly D, Jones A. When care is needed: the role of whistleblowing in promoting best standards from an individual and organizational perspective. Qual Ageing Older Adults. 2013;14(30):180-191.

4. Jones A, Kelly D. Whistle-blowing and workplace culture in older peoples' care: qualitative insights from the healthcare and social care workforce. Soc Health Illn. 2014;36(7):986-1002.

5. Bernoth M, Dietsch E, Kisalay Burmeister O, Schwartz M. Information management in aged care: cases of confidentiality and elder abuse. J Bus Ethics. 2014;122:453-460.

6. Carp FM. Elder Abuse in the Family. New York: Springer Publishing Company; 2000.

7. United Nations Political Declaration and Madrid Action Plan on Ageing. New York: UN; 2002. http://www.un.org/en/events/pastevents/pdfs/ Madrid_plan.pdf. Accessed October 01, 2014. 
8. World Health Organisation Aging and Life Course: Facts About Aging. 2015. Available from: http://www.who.int/ageing/about/facts/en/. Accessed April 7, 2015.

9. Neugarten BL. Age groups in American Society and the rise of the young-old. Ann Am Acad Pol Soc Sci. 1974;415:187-198.

10. United Nations World Population Ageing. New York: UN; 2013. http:// www.un.org/en/development/desa/population/publications/pdf/ageing/ WorldPopulationAgeing2013.pdf. Accessed June 05, 2015.

11. Kamiya Y. Changing Age Structures and Their Impact. 2015. Available from: http://www.un.org/en/development/desa/population/events/ expert-group/22/3_aging.shtml. Accessed May 21, 2015.

12. Wren MA, Normand C, O'Reilly D, Cruise SM, Connolly S, Murphy C. Towards the Development of a Predictive Model of Long-Term Care Demand for Northern Ireland and the Republic of Ireland. Galway: Centre for Health Policy Management, TCD, Centre for Public Health, QUB and the Irish Centre for Gerontology NUI. 2012.

13. Spilsbury K, Hewitt C, Stirk L, Bowman C. The relationship between nurse staffing and quality of care in nursing homes: a systematic review. Int J Nurs Stud. 2011;48(6):732-750.

14. Baker AA. Granny bashing. Mod Geriatr. 1975;8:20-24.

15. Phelan A. International Perspectives on Elder Abuse. London: Routledge; 2013.

16. United Nations Elder Abuse: A Violation of Older People's Rights. ND. Available from: http://www.un.org/en/events/elderabuse/background. shtml. Accessed June 04, 2015.

17. World Health Organisation Toronto Declaration on Elder Abuse. Geneva: WHO; 2002.

18. Action on Elder Abuse. Action on Elder Abuse: Bulletin 1. London: Action on Elder Abuse; 1995.

19. Mowlam A, Tennant R, Dixon J, McCreadie C. UK Study of Abuse and Neglect of Older People: Qualitative Findings. London: King's College London and the National Centre for Social Research. 2007.

20. World Health Organization. Missing Voices: Views of Older Persons on Elder Abuse. Geneva: World Health Organization; 2002. Available from: http://apps.who.int/iris/bitstream/10665/67371/1/ WHO_NMH_VIP_02.1.pdf.

21. Erlingsson CI, Saveman BI, Berg AC. Perceptions of elder abuse: voices of older persons. Brief Treat Crisis Inter. 2005;5(2):213-227.

22. Lafferty A, Treacy MP, Fealy G, Drennan J, Lyons I. Older People's Experiences of Mistreatment and Abuse. Dublin: NCPOP; 2012.

23. Anand J, Begley E, O’Brien M, Taylor B, Killick C. Conceptualising elder abuse across local and global contexts: implications for policy and professional practice on the island. J Adult Prot. 2013;15(6): 280-290.

24. O' Keefe M, Hills A, Doyle M, et al. United Kingdom Study of Abuse and Neglect of Older People. London: King's College London and the National Centre for Social Research. 2007.

25. Naughton C, Drennan J, Treacy MP, et al. Abuse and Neglect of Older People in Ireland; Report on the National Study of Elder Abuse and Neglect. Dublin: NCPOP; 2010.

26. Acierno R, Hernandez MA, Amstadter AB, et al. Prevalence and correlates of emotional, physical, sexual, and financial abuse and potential neglect in the United States: the national elder mistreatment study. Am J Public Health. 2010;100(2):292-297.

27. Lifespan of Greater Rochester Inc. Under the Radar: New York State Elder Abuse Study. New York: Weill Medical School, Cornell University, Department of Aging; 2011. Available from: http://nyceac.com/ wp-content/uploads/2011/05/UndertheRadar051211.pdf. Accessed May 20, 2015.

28. Cooper C, Manela M, Katona C, Livingston G. Screening for elder abuse in dementia in the LASER-AD study: prevalence, correlates and validation of instruments. Int J Geriatr Psychiatry. 2008;23(3):283-288.

29. Yan E, Kwok T. Abuse of older Chinese with dementia by family caregivers: an inquiry into the role of caregiver burden. Int Geriatr Psychiatry. 2011;26:527-535.

30. Pillemer K, Moore DW. Abuse of patients in nursing homes: findings from a staff survey. Gerontologist. 1989;19(3):314-320.
31. Phillips LR, Guo G. Mistreatment in assisted living facilities: complaints, substantiations and risk factors. Gerontologist. 2011;51:343-353.

32. Drennan J, Lafferty A, Treacy MP, et al. Older People in Residential Care Settings: Results from a National Survey of Staff-Resident Interactions and Conflicts. Dublin: NCPOP.

33. Townend P. The Last Refuge a Survey of Residential Institutions and Homes for the Aged in England and Wales. London: Routledge and Kegan Paul; 1962.

34. Stannard C. Old folks and dirty work: the social conditions for patient abuse in a nursing home. Soc Probl. 1973;20(3):329-342.

35. Lachs M, Williams C, O'Brien S, Hurst L, Horwitz R. Risk factors for reported elder abuse and beglect: a nine year observational cohort study. Gerontologist. 1997;37(4):469-474.

36. McDonald L, Beaulieu M, Harbison J, et al. Institutional abuse of older adults: what we know and what we need to know. J Elder Abuse Negl. 2012;24(2):138-160.

37. Isola A, Backman K, Voutilainen P, Rautsiala T. Quality of institutional care of older people as evaluated by nursing staff. J Clin Nurs. 2008; 17(18):2480-2489.

38. Page C, Conner T, Prokhorov A, Fang Y, Post L. The effect of care setting on elder abuse: results from a Michigan survey. J Elder Abuse Negl. 2009;21(3):239-252.

39. Goergen T. A multi-method study on elder abuse and neglect in nursing homes. J Adult Prot. 2004;6(3):15-25.

40. Ben Nathan M, Lowenstein A. Psycho-social factors affecting elders' maltreatment in long-term facilities. Int Nurs Rev. 2010;57(1): 113-120.

41. Lindbloom EJ, Brandt J, Hough LD, Meadows SE. Elder mistreatment in the nursing home: a systematic review. J Am Med Dir Ass. 2007; 8(9):610-616.

42. Griffore RJ, Barboza GE, Mastin T, Oehmke J, Schiamberg LB, Post LA. Family members' reports of abuse in Michigan nursing homes. J Elder Abuse Negl. 2009;21(2):105-114.

43. Malmedal W, Ingebrigtsen O, Saveman BI. Inadequate care in Norwegian nursing homes - as reported by nursing staff. Scand J Caring Sci. 2009;23(2):231-242.

44. Bužgová R, Ivanová K. Violation of ethical principles in institutional care for older people. Nurs Ethics. 2011;18(1):64-78.

45. Hyde P, Burns D, Killett A, Kenkmann A, Poland F, Gray R. Organisational aspects of elder mistreatment in long term care. Qual Ageing Older Adults. 2014;15(4):197-209.

46. Harrow Council Institutional Abuse ND. Available from: http://www. harrow.gov.uk/info/200184/adults_at_risk/749/institutional_abuse. Accessed March 01, 2015.

47. Jogerst G, Daly J, Dawson J, Peek-Asa C, Schmuch G. Iowa nursing home characteristics associated with reported abuse. J Am Med Dir Assoc. 2006;7(4):203-207.

48. Clarfield M, Ginsberg G, Rasooly I, Levis A, Gindind J, Dwolatzky T. For profit and not for profit nursing homes in Israel: do they differe with respect for quality of care? Arch Gerontol Geriatr. 2009; 48(2): 167-172.

49. US Government Accountability Office Private Investment Homes Sometimes Differed from Others in Deficiencies, Staffing, and Financial Performance. Washington DC: Government Accountability Office.

50. Ekici A, Onsel S. How ethical behavior of firms is influenced by the legal and political environments: a Bayesian casual map analysis based on stages of development. J Bus Ethics. 2012;115:271-290.

51. Phelan A. Elder abuse, human rights, citizenship: implications for nursing discourse. Nurs Inq. 2008;15(4):320-330.

52. Working Group on Elder Abuse Protecting Our Future. Dublin: Stationery Office; 2002.

53. Ayton-Shenker D. The Challenge of Human Rights and Cultural Diversity. 1995. Available from: http://www.un.org/rights/dpi1627ehtm. Accessed April 30, 2015.

54. Mangan I. Older People in Long Stay Care. Dublin: Irish Human Rights Committee; 2003. 
55. INPEA, IFA, ILC-US, et al. Strengthening Older People's Rights: Towards a UN Convention. 2010. Available from: http://www.cardi. ie/userfiles/UN\%20NGO $\% 20-\% 20$ Strengthening\%20Older $\% 20$ People\%27s\%20Rights\%283\%29.pdf. Accessed January 10, 2013.

56. Murphy M. International human rights law and older people: Gaps, fragments and loophole. HelpAge Intermnational 2012. Available from: http://social.un.org/ageing-working-group/documents/Gapsinprotectio nofolderpeoplesrightsAugust2012.pdf. Accessed March 21, 2015.

57. Kane RL. Kane RAAgeism in healthcare and long-termcare. Generations. 2005;29(3):49-54.

58. Quinn G. Age: From Human Deficits to Human Rights - Reflections on a Changing Field. 2013 Launch Event Human Rights and Older People Working Group 'Human Rights and Older People in Ireland' - Policy Paper. Available from: https://www.alzheimer.ie/Alzheimer/media/ SiteMedia/ImageSlider/Fixed/ASI-HROP-A4-Online-Report.pdf. Accessed November 5, 2015.

59. World Health Organization. Developing Sexual Health Programmes: A Framework for Action. Geneva: World Health Organization; 2010. Available from: http://apps.who.int/iris/bitstream/10665/70501/1/ WHO_RHR_HRP_10.22_eng.pdf. Accessed November 5, 2015.

60. Benbow SM, Beeston D. Sexuality, aging, and dementia. Intern Psychogeriatr. 2012;27(7):1026-1033.

61. Callan MR. Providing aged care services for the gay and lesbian community. Aus Nurs J. 2006;14:20.

62. Cerejeira J, Largarto L, Mukaetova-Ladinska EB. Behavioural and psychological symptoms of dementia. Front Neuro. 2012;3(73):1-21.

63. Bonifas P. Resident-to-resident aggression in nursing homes: social worker involvement and collaboration with nursing colleague. Health Soc Work. 2015;40(3):e101-e109.

64. Pillemer K, Chen EK, Van Haitsma KS, et al. Resident-to-resident aggression in nursing homes: results from a qualitative event reconstruction study. Gerontologist. 2012;52(1):24-33.

65. Zhang Z, Page C, Conner T, Post LA. Family members' reports of non-staff abuse in Michigan nursing homes. J Elder Abuse Negl. 2012; 24(4):357-369.

66. Trompetter H, Scholte R, Westerhof G. Resident-to-resident relational aggression and subjective well-being in assisted living facilities. Aging Men Health. 2011;15(1):59-67.

67. Lapuk DS. Resident Aggression in a Long Terms Care Setting: Concerns and Meanings from Perspectives of Other Residents [Unpublished Doctoral dissertation]. Manitoba: University of Manitoba; 2007.

68. Lachs M, Bachman R, Eilliams SC, O'Leary JR. Resident to resident mistreatment and police contact in nursing homes: findings form a population based cohort. J Am Geriatr Soc. 2007;55(6):840-845.

69. Rosen T, Lachs M, Bharucha AJ, et al. Resident-to-resident aggression in long-term care facilities: insights from focus groups of nursing home residents and staff. J Am Geriatr Soc. 2008;56(8):1398-1408.

70. Morgan DG, Cammer A, Stewart NJ, et al. Nursing aide reports of combative behavior by residnts with dementia: results from a detailed prospective incident diary. J Am Med Dir Assoc. 2012;13:220-227.

71. Health Information and Quality Authority Analysis of Nursing Homes (July 3rd). Dublin: HIQA; 2015.

72. The Commission of Investigation (Leas Cross Nursing Home). 2 Final Report June 2009. 2009. Available from: http://health.gov.ie/wp-content/ uploads/2014/03/leascross.pdf. Accessed March 3, 2015.

73. Francis R. Mid Staffordshire NHS Foundation Trust Public Inquiry. London: Stationery Office; 2013.

Risk Management and Healthcare Policy

\section{Publish your work in this journal}

Risk Management and Healthcare Policy is an international, peerreviewed, open access journal focusing on all aspects of public health, policy, and preventative measures to promote good health and improve morbidity and mortality in the population. The journal welcomes submitted papers covering original research, basic science, clinical \& epidemio-
74. Radio Televis Eireann. Primetime Investigates: Home Truths. 2005. Available from: https://www.youtube.com/watch?v=WuCNXUzV2uM. Accessed March 21, 2015.

75. Manthorpe J, Martineau S. Serious case reviews into dementia care: an analysis of context and content. B J Soc Work. 2014.

76. Nottingham Safeguarding Adults Board Serious Case Reviews 2015; 2015. Available from: http://www.nottinghamcity.gov.uk/article/23734/ Serious-Case-Reviews. Accessed June 2015.

77. McCormack B, Dewing J, Breslin E, et al. Developing person-centred practice: nursing outcomes arising from changes to the care environment in residential settings for older people. Int J Older People Nurs. 2010;5:93-107.

78. McCormack B, McCance T. Person-Centred Nursing: Theory and Practice. Oxford: Wiley Blackwell; 2010.

79. Department of Health National Positive Ageing Strategy. Dublin: Stationery Office; 2013. http://health.gov.ie/healthy-ireland/nationalpositive-ageing-strategy. Accessed November 5, 2015.

80. Health Information and Quality Authority Draft Standards for Residential Care Settings for Older People in Ireland. Dublin: HIQA; 2014. Available from http://www.hiqa.ie/publications/draft-nationalstandards-residential-care-settings-older-people-ireland-2014. Accessed November 5, 2015.

81. Bronfenbrenner U. The Ecology of Human Development: Experiments by Nature and Design. Cambridge, MA: Harvard University Press; 1979.

82. Kalisch B. Missed care: a qualitative study. J Nurs Care Qual. 2006; 21(4):306-313.

83. Clarke S, Aiken L. Failure to rescue. Am J Nurs. 2004;103(1):42-47.

84. Fisk RJ. What are never events and why do they matter? Health Lawyer. 2008;21(1):34-37.

85. Munby J. 11 CCL Rep 119, [2008] Fam Law 213, [2007] EWHC 2003 (Fam), [2009] 1 FLR 443, [2008] 3 FCR 788; 2008.

86. Health Service Executive Risk Management in the HSE: An Information Booklet. Dublin: HSE.

87. Lafferty A, Phelan A, Fealy G. Residential Care Standards: Towards a Risk-management Framework for Preventing Elder Mistreatment. NCPOP: University College Dublin. Available from: http://www.ncpop. ie/userfiles/file/ncpop\%20reports/Non-Com_ResCareStandards_WEB. pdf. Accessed November 5, 2015.

88. Gironda MW, Lefever K, Delagrammatikas L, et al. Education and training of mandated reporters: Innovative models, overcoming challenges and lessons learned. J Elder Abuse Negl. 2010;22(2/3):340-364.

89. Fealy G, O'Donnell D, Patton D, Downes C, O' Connor T. An Evaluation of the HSE National Training Programme in Preventing Elder Abuse. Dublin: NCPOP; 2014.

90. Smith MK, Davis BH, Blowers A, Shenk D, Jackson K, Kaslaw K. Twelve important minutes: introducing enhanced on line materials about elder abuse to nursing assistants. $J$ Contin Ed Nurs. 2010; 46(1):281-288.

91. Holohan 2014 HSE Midland Regional Hospital, Portlaoise Perinatal Deaths. Dublin: Department of Health; 2006.

92. Gallagher A. Whistleblowing: What Influences Nurses' Decisions on Whether to Report Poor Practice. Nursing Times; 2010. Available from: http://www.nursingtimes.net/nursing-practice/leadership/ whistleblowing-what-influences-nurses-decisions-on-whether-toreport-poor-practice/5010979.article. Accessed November 5, 2015.

93. Attree M. Factors influencing nurses' decisions to raise concerns about care quality. J Nurs Mang. 2007;15(4):392-402.

\section{Dovepress}

logical studies, reviews and evaluations, guidelines, expert opinion and commentary, case reports and extended reports. The manuscript management system is completely online and includes a very quick and fair peerreview system, which is all easy to use. Visit http://www.dovepress.com/ testimonials.php to read real quotes from published authors. 